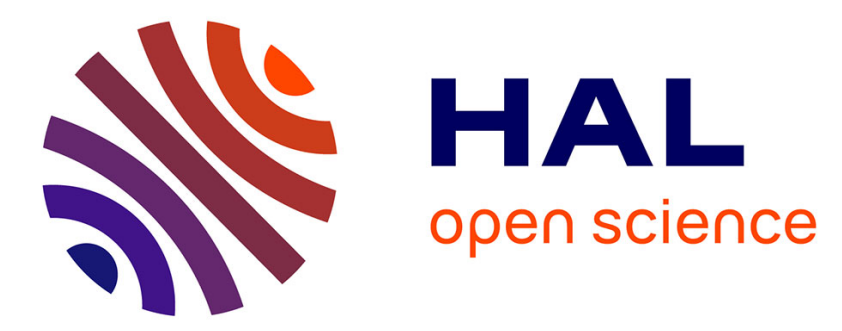

\title{
The role of novelty detection in food memory
}

Leri Morin-Audebrand, Jos Mojet, Claire Chabanet, Sylvie Issanchou, Per

Moller, Egon Peter Köster, Claire Sulmont-Rossé

\section{To cite this version:}

Leri Morin-Audebrand, Jos Mojet, Claire Chabanet, Sylvie Issanchou, Per Moller, et al.. The role of novelty detection in food memory. Acta Psychologica, 2012, 139 (1), pp.233-238. 10.1016/j.actpsy.2011.10.003 . hal-02643472

\section{HAL Id: hal-02643472 \\ https://hal.inrae.fr/hal-02643472}

Submitted on 6 Jan 2022

HAL is a multi-disciplinary open access archive for the deposit and dissemination of scientific research documents, whether they are published or not. The documents may come from teaching and research institutions in France or abroad, or from public or private research centers.
L'archive ouverte pluridisciplinaire $\mathbf{H A L}$, est destinée au dépôt et à la diffusion de documents scientifiques de niveau recherche, publiés ou non, émanant des établissements d'enseignement et de recherche français ou étrangers, des laboratoires publics ou privés. 
1 The role of novelty detection in food memory

2 Léri Morin-Audebrand $^{\mathrm{a} 1}$, Jos Mojet ${ }^{\mathrm{b}}$, Claire Chabanet ${ }^{\mathrm{a}}$, Sylvie Issanchou ${ }^{\mathrm{a}}$, Per Møller,

3 Ep Köster ${ }^{\mathrm{b}}$, and Claire Sulmont-Rossé ${ }^{\mathrm{a}}$

$4{ }^{\text {a }}$ Centre des Sciences du Goût et de l'Alimentation, UMR6265 CNRS, UMR1324 INRA,

5 Université de Bourgogne, Agrosup Dijon, F-21000 Dijon, France; ${ }^{b}$ Center for Innovative

6 Consumer Studies, Wageningen University and Research, The Netherlands; ${ }^{c}$ Faculty of LIFE

7 Sciences, University of Copenhagen, Denmark

8 Corresponding author: Sylvie.Issanchou@dijon.inra.fr

9 Address: Centre INRA, 17 rue Sully, BP 86510, 21065 Dijon cedex.

10 Tel. +33380693076, Fax +33380693227

\footnotetext{
${ }^{1}$ Present address: Nestlé Research Center, Sensory and Consumer Sciences Group, PO Box 44, CH-1000 Lausanne 26, Switzerland
} 


\section{ABSTRACT}

13 Memory plays a central role in food choice. Recent studies focusing on food memory in 14 everyday eating and drinking behaviour used a paradigm based on incidental learning of 15 target foods and unexpected memory testing, demanding recognition of the target amongst 16 distractors, which deviate slightly from the target. Results question the traditional view of 17 memory as reactivation of previous experiences. Comparison of data from several 18 experiments shows that in incidentally learned memory, distractors are rejected, while 19 original targets are not recognised better than by chance guessing. Food memory is tuned at 20 detecting novelty and change, rather than at recognizing a previously encountered food.

22 Keywords: Incidental learning; Recognition; Signal detection theory; Memory function. 


\section{INTRODUCTION}

26 Eating, drinking and food choice are among the most frequent and most important human 27 behaviours. Although seemingly simple, they are in fact very complex behaviours in which 28 many physiological and psychological factors interact. Among these factors learning and memory play a central role. Almost all food preferences, with the exception of an inborn dislike for bitterness and an attraction to sweetness, are learned and a very substantial part of this learning takes place at a very early age and in some cases even prenatally (Hausner et al., 2010; Mennella et al., 2001; Schaal et al., 2002). The forms of learning involved are also extremely diverse, varying from imprinting (Haller et al., 1999), flavour-nutrient conditioning (Yeomans et al., 2008) and flavour-flavour conditioning (Stevenson et al., 1995) to imitation (Birch, 1980), but these forms are almost never intentional or explicit and memory for food is also to a very large extent implicit (for a review, see Köster and Mojet, 2007a, 2007b). Most of us cannot describe the food we eat in any detail, but we are usually very keen in noticing changes in its flavour or texture. Odour memory is more acute in detecting off-odours than visual memory in detecting off-colours (Møller et al., 2009) and people may spend a long time finding the 10 differences between two similar pictures in visual puzzles, but will usually immediately notice the slightest differences in the odour, flavour and texture (mouthfeel) of foods, although they can not describe them. Olfaction and touch are also the two senses that are subject to complete adaptation. This means that the absolute sensitivity to a continuous stimulus is completely lost, but that the sensitivity to new or stronger stimuli remains and may even become more acute (Mojet et al., 2003). Thus, an incidentally learned implicit memory that differs from verbal memory and memory for visual information seems to be functional in eating and drinking behaviour. Strangely enough, the existence of an area of behaviour that 
through its special characteristics seems to be the ideal terrain to study the functioning of incidental learning and implicit behaviour, has escaped the attention of most memory psychologists, who were either involved in verbal learning and memory or studied odour memory in the same way as verbal or object memory, devoting much attention to identification (Cain et al., 1998; Rabin and Cain, 1984). Nevertheless, over the last few years several groups of researchers have started to study the role of memory in eating and drinking in a different way. Presentation of some of their main results to other psychologists is the main object of this paper. In presenting it, two points should be made clear:

1) All authors (the same as the present authors) wanted to study the function of memory in a way that avoided experimental artefacts and guaranteed external ecological validity as much as possible. They were concerned with the reductionism of much laboratory research which threatens to be non representative of the functioning of the studied phenomena in real life. A new paradigm for incidental learning under normal eating circumstances was developed to this purpose.

2) The present paper deals only with one of the many forms of learning involved in food memory and is basically concerned with the question: "What sensory information is retained spontaneously in a normal eating situation and how is it retained?" The main concern is therefore to investigate the generality of the functioning of incidentally learned food memory throughout a number of different experimental settings, varying not only in using subjects of different age, gender and eating culture, but also in such experimental factors as the duration of the retention interval and the target/distractor ratio in the recognition tests. The invariance of certain memory features over such very diverse experimental circumstances is therefore considered to be the most important outcome of the paper. It not only shows the robustness of these features, but also questions the generality of certain methodological viewpoints in memory research. 
73 A number of studies (Laureati et al., 2008; Mojet and Köster, 2002; Mojet and Köster, 2005; 74 Møller et al., 2007; Sulmont-Rossé et al., 2008) investigated food memory with a new paradigm. In all of the experiments the subjects were invited to have a breakfast or a meal in the laboratory under a false pretence. Depending on the studies, the subjects were informed that they would be offered a meal to study their post-meal hunger feelings or that they would 78 be offered a meal as a break between experiments that "took long or took place at awkward 79 times" (e.g. before and after lunch time). After the meal which contained one or more "target" 80 foods or drinks they returned to their own activities. No special attention was given to the 81 hidden targets and memory was never mentioned. Only when the participants later came back 82 for a second session, it became clear to them that they were to be tested on their memory for 83 some of the food items they had eaten during that first meal. They received samples of the 84 targets and distractors that had been made by varying the intensity of one of the sensory 85 characteristics of the food (e.g. sweetness or viscosity) by small amounts or by varying the nature of the sensory characteristics of the food slightly (e.g. by adding a small amount of a new aroma component). Debriefing before the second session showed that none of the participants had guessed the true purpose of the experiment. In this way the artificiality of eating in a laboratory situation was circumvented and an unintentional learning situation was created that was comparable to a normal meal.

This paradigm differs from classic recognition experiments on olfactory and taste memory (Herz and Engen, 1996; Larsson, 1997) in several respects.

Firstly, in the learning phase of classic experiments clearly different stimuli are presented out of context and must later be recognised amongst other clearly distinct new stimuli. In the new memory paradigm, the targets are inconspicuous, since they are not presented out of context as individual items, but embedded in a natural meal setting. 
97 Secondly, the number of target foods used is below the number of stimuli used in classic 98 recognition experiments. In odour recognition tests, this number varies from 10 to 48 (Engen 99 and Ross, 1973; Lawless and Cain, 1975; Lehrner, 1993; Lyman and McDaniel, 1990; 100 Murphy et al., 1991). To avoid satiety effects, in the present experiment at most 3 targets are 101 learned, and recognition series contain maximally 12 samples.

102 Thirdly, the distractors differed only slightly from the target by a just-noticeable (perceptual 103 discrimination in $50 \%$ of the cases) intensity variation of one of their characteristics (e.g. 104 sweetness, viscosity or crispiness) or by the addition of small amounts of a different 105 ingredient (e.g. a tinge of some flavour) that left the overall sensory impression of the target 106 intact. This was checked through preliminary experiments run with participants different from 107 those who took part in the main study. Thus, all distractors still belonged to the same product 108 space as the targets (e.g. all distractors of orange juice would still be identified as orange 109 juice). As a result verbal memory by stimulus name could not play a role in the recognition 110 test of the new paradigm, whereas in the classical recognition experiments with its very 111 different distractors, it always mingles with the purely sensory based memory, even when 112 uncommon odours or flavours are used for which people may create their own names. Finally, 113 in the classic view, learning involves formation of mental representations of the learned items. 114 Memory and recognition are based on storage and retrieval of these representations. The new 115 paradigm makes no pre-conceived assumptions about memory. It simply observes peoples' 116 reactions to slightly altered or the same foods as they have eaten previously in a meal without 117 paying special attention to the food and without any intent to memorise it.

118 This paper presents a systematic and homogeneous analysis of the merged data from 6 studies 119 (see table 1) with the new paradigm, in order to extract some 'general characteristics' of food 120 memory. In all of these incidental learning studies, memory seemed to be based on correct 
121 rejection of distractor samples rather than on correct recognition of the target. This suggests 122 that participants use detection of novelty or change, rather than recollection and recognition of 123 earlier experienced and encoded sensory stimulus patterns. In the experiments presented here, 124 this hypothesis was tested in a variety of experimental conditions, to see whether it would 125 keep up under different circumstances and to what extent it would be influenced by factors 126 like gender, age and variation of experimental variables, such as the nature of the difference 127 between targets and distractors and the signal probability in the memory tests. It is hoped that 128 the overview of the results given here may contribute to the understanding of the actual 129 functioning of memory in the lower senses and in incidentally learned behaviours and that it 130 may stimulate research along the same lines in other sensory areas such as kinaesthesia, 131 touch, audition and vision.

\section{2. MATERIAL AND METHODS}

\section{2.1. Data sets}

134 Table 1 summarizes the main characteristics of the six studies. All six studies investigated 135 food memory by using the new paradigm described in the introduction.

\section{Table 1 about here}

137 The data of 397 participants are included. In most studies, the men/women ratio was almost 138 balanced. Age varied from 17 to 84 . In studies S3, S4 and S5, participants were recruited 139 among two discrete age groups. Different subjects were used in all experiments. Once they 140 had taken part in the memory experiment they were never asked to participate in memory 141 experiments again, unless only intentional learning and memory were involved. In all studies 142 but S3, participants were led to believe that they took part in a study on hunger feelings. In 
143 S3, during an interval in another long experiment participants were offered new soups as a 144 snack and were casually asked their opinion about them. Since in all studies but S3, 145 participants were led to believe that they took part in a study on hunger feelings, they were 146 told to eat the complete amount served, under the pretence it had been standardized on energy 147 content. In S3, participants were asked to eat the total amount of soup in order to be able to 148 give their global appreciation of the soups after the lunch. Data from participants who did not 149 eat the whole portion of each target food were excluded from the study. Depending on the 150 study, participants were exposed to respectively 1 (S5), 2 (S3, S4) or even 3 (S1, S2) target 151 foods. In S6, participants were exposed to two target custards in two different learning meals. 152 In order to be able to separate the effect of episodic learning from everyday familiarity, the 153 target stimuli always deviated somewhat from the regular market products.

154 Memory test

155 After $8 \mathrm{hrs}, 24 \mathrm{hrs}$ or 1 week, depending on the study, participants came back for an 156 unexpected test session. They received recognition series including targets (same as the foods 157 in the learning phase) and distractors, prepared either by varying the concentration of one 158 ingredient in the target (quantitative variation - S1, S2, S4, S5), or by adding a new flavour 159 the target (qualitative variation - S3, S6). All distractors were selected in a preliminary 160 experiment to be noticeably, but not too obviously, different from the target. In S1, S4 and S5, 161 the Just Noticeable Difference (JND), i.e. the smallest difference perceived by $50 \%$ of the 162 population, was estimated for each compound and for each food model (see Köster et al., 1632004 , for an exhaustive account of this procedure). The range of the difference between the 164 targets and the distractors was -2 JND to +2 JND. In S2, the distribution of the targets and the 165 descriptors in the sensory space was checked by a sensory panel trained in quantitative 166 descriptive analysis (QDA). In S6 \& S3, the perceptual distances between distractors and 167 targets were checked and matched through similarity tests. Depending on the study, 
168 recognition series included 4-12 samples with target/distractor ratios varying from 1:1 to 1:3.

169 If several foods were involved, memory for each food was tested with a separate recognition 170 series. Participants indicated whether each sample was the same as or different from the one 171 consumed during the learning phase. In all studies but S3, participants also indicated their 172 certainty about their decision (confidence rating). Finally, in all studies but S4, participants 173 rated their liking for each target and distractor, using a separate set of newly coded stimuli.

\section{2.2. Data analysis}

175 Two indices, derived from Signal Detection Theory (Macmillan and Creelman, 2005), but 176 adapted to the needs of experiments with low numbers of stimuli, a recognition index 177 comparable to d' and a bias index similar to C, were used. Although the indices $d$ ' and $C$, 178 which require probit transformation of the response proportions, are most widely used, they 179 are less apt for use with small sets of stimuli in which proportions of 0 and 1 occur frequently. 180 Therefore an empirical logit transformation (Cox, 1970), was used to deal with extreme 181 proportions:

182 Recognition index $=\log \left[\left(\mathrm{N}_{\mathrm{H}}+0.5\right) /\left(\mathrm{N}_{\mathrm{M}}+0.5\right)\right]-\log \left[\left(\mathrm{N}_{\mathrm{FA}}+0.5\right) /\left(\mathrm{N}_{\mathrm{CR}}+0.5\right)\right]$

183 Bias index $=-\log \left[\left(\mathrm{N}_{\mathrm{H}}+\mathrm{N}_{\mathrm{FA}}+0.5\right) /\left(\mathrm{N}_{\mathrm{M}}+\mathrm{N}_{\mathrm{CR}}+0.5\right)\right]$

184 with $\mathrm{N}_{\mathrm{H}}, \mathrm{N}_{\mathrm{M}}, \mathrm{N}_{\mathrm{FA}}$ and $\mathrm{N}_{\mathrm{CR}}$ respectively corresponding to the numbers of hits, misses, false 185 alarms and correct rejections.

186 With regard to memory strength, a recognition index higher than zero means that participants 187 answered more often "same" for the target samples than for the distractor samples, i.e. that a 188 memory effect occurred. With regard to response bias, a bias higher than zero means that 189 participants had a bias to answer "different" when uncertain about to which class of items 190 stimuli belong. As stated by Signal Detection Theory and similarly to d' and C, these two 
191 indices are independent: one could recognize the targets and, nevertheless has a bias to answer 192 "different".

193 These indices were calculated for each participant and for each of the 12 recognition series 194 (each corresponding to a food in a given study). Confidence and liking ratings were converted 195 into scores ranging from 0 (not sure/ disliked) to 10 (sure/liked).

196 Statistical analyses were conducted using the SAS/STAT ${ }^{\circledR}$ version 9.1 statistical software 197 package (SAS Institute Inc., Cary, USA). All analyses were performed with the MIXED 198 procedure of SAS. Post-hoc comparisons of means were computed for each significant factor 199 by using the lsmeans option of the MIXED procedure. All results reported are significant at 200 the $\mathrm{P}<0.05$ level. Student statistics were used to assess whether indices were significantly 201 different from zero. Confidence intervals derived from linear mixed models are reported.

\section{3. RESULTS}

203 3.1. Food memory performance: an overview

\section{3.1.1. Recognition performance}

205 Figure 1 depicts the average proportions of hits, misses, false alarms and correct rejections 206 over all recognition series, resulting in a significantly higher than zero recognition index $207\left(M=0.59, S E=0.05, t_{782}=11.51, p<0.001\right)$ and a positive bias index, $(M=0.69, S E=0.03$, 
214 The large number of observations allows reliable determination of hit and false alarm 215 proportions for each position in the recognition series (Figure 2) and makes it possible to 216 check whether target recognition increases over the recognition sequence. Both proportions 12 increased, indicating that participants' bias to answer "different" decreases as they went along the series. However, the hit proportion never rose above 50\% and false alarm proportions remained lower on all positions.

\section{FIGURE 2 about here}

\subsubsection{Confidence rating}

An analysis on confidence ratings with response category (hit, miss, false alarm and correct rejection) as a fixed factor and recognition series as random, revealed a significant effect of response category $\left(F_{3,27}=19.34 ; p<.001\right)$. A post-hoc comparison showed correct rejections to receive the highest $(M=6.91 ; S E=0.43)$ and hits and false alarms the lowest confidence scores, with misses intermediate and differing significantly from all 3 others (hit: $M=5.01 ; S E=0.44$; false alarms: $M=5.11 ; S E=0.44 ;$ misses: $M=5.71 ; S E=0.43)$. Participants showed more confidence in their "different" than in their "same" responses, and much more in their correct rejections than in their hits.

\subsubsection{Liking rating}

An analysis on liking scores with response category (hit, miss, false alarm and correct rejection) as a fixed factor and recognition series as random revealed a significant effect of response category $\left(F_{3,27}=4.19 ; p<.01\right)$. Post-hoc comparison showed that correct rejections were associated with lower liking scores $(M=3.88 ; S E=0.29)$ than the three other response 
categories (misses: $M=4.58 ; S E=0.30$; false alarms: $M=4.68 ; S E=0.30$; hits: $M=4.93$; $S E=0.30)$.

\subsection{Effect of participant-dependent factors on memory performance}

\subsubsection{Effect of gender and age}

239 An analysis with gender as a fixed factor and recognition series as random, showed that 240 gender had no effect on recognition $\left(F_{1,11}=0.01 ; p>.05\right)$ but a significant effect on bias $241\left(F_{1,11}=13.36 ; p<.01\right)$. Women $\left(M=0.80 ; S E=0.09 ; t_{11}=8.67 ; p<.001\right)$ had a significantly higher 242 bias index than men $\left(M=0.58 ; S E=0.09 ; t_{11}=6.18 ; p<.001\right)$.

243 The effect of age on memory performance was assessed in data from S3, S4 and S5 which 244 included groups of less than 50 year old and of over 50 year old adults. Recognition and bias 245 indices were analysed with age group as a fixed factor and recognition series as random. 246 There was no effect of age on recognition $\left(F_{1,4}=0.11 ; p>.05\right)$ or on bias $\left(F_{1,4}=1.32 ; p>.05\right)$.

\section{3.3. Effect of experimental variables on memory performance}

248 A separate analysis was performed for each factor, since the levels of these factors were not 249 systematically crossed between the recognition series.

\section{3.3.1. Target/distractor ratio}

251 According to signal detection theory (Macmillan and Creelman, 2005), a target/distractor 252 ratio of 1:1 is ideal, because other ratios, when known to or detected by the participants, may 253 influence their response bias. In the present studies, the ratio is often unbalanced in favour of 254 a higher number of (different) distractors. In classic recognition tests, participants are exposed 255 to many different targets during learning, and receive each target once in the recognition 
256 series. In the present paradigm, participants are exposed to only one target per food while

257 learning. To reach a 1:1 target distractor ratio, it would be necessary to present this target as 258 many times as there are distractors. This might lead to unwanted incidental learning effects, 259 since only the target would appear repeatedly. Allowing other ratios reduces this risk. It was 260 checked whether the unbalanced ratios had an impact on the responses, although participants 261 were unaware of the signal probability and the short test series prevented implicit learning 262 about the ratio. The ratio-effect was significant for recognition $\left(F_{3,40}=12.86 ; p<.001\right)$, but not 263 for bias $\left(F_{3,40}=1.30 ; p>.05\right)$, indicating that there was no influence of the unbalanced ratios 264 upon response behaviour.

\subsubsection{Nature of the difference between targets and distractors}

Analyses showed a significant effect of variation (quantitative-qualitative) on recognition $\left(F_{1,43}=29.81 ; p<.001\right)$, but not on bias $\left(F_{1,43}=0.04 ; p>.05\right)$. The over all significant recognition indices were higher for qualitative $\left(M=1.25 ; S E=0.13 ; t_{43}=9.45 ; p<.001\right)$ than for quantitative variations $\left(M=0.46 ; S E=0.06 ; t_{43}=7.96 ; p<.001\right)$. Obviously, new features stand out more clearly as novel than intensity variations.

\section{DISCUSSION}

Before discussing the main results of the experiments and their contribution to an understanding of the role and functioning of incidentally learned memory in eating and drinking behaviour and to memory theory in general, the effects of some of the variables that are supposed to influence memory performance will be considered shortly. Despite the fact that results may be biased because of the limited sample of studies (up to our knowledge, we gathered all the studies that used the paradigm proposed by Köster), the present paper is the 
278 first to pool, in a global data set, the results of six independent studies on food memory based

on the same innovative paradigm. Although this allows drawing reliable conclusions about the general food memory processes, discussions about the effect of the variables age, target/distractor ratio and nature of the food variations should be considered with caution as the level of these factors were not systematically crossed between the recognition series.

\subsection{Gender differences}

284 In classic recognition experiments using well-known odours, women often show better odour 285 memory than men (Lehrner, 1993). However, such a gender effect disappeared when verbal 286 capacity was controlled for (Larsson et al., 2003; Monnery-Patris et al., 2009). As stated by 287 Larsson et al. (2003), the finding that the observed female superiority in odour recognition 288 disappeared when verbal proficiency was controlled for suggests that a gender difference in 289 recognition memory is mediated by female superiority in verbal processing. With the 290 incidental learning paradigm used here, this advantage is lost, since the basic flavour remains 291 the same and therefore semantic information is not helpful. This is corroborated by Møller et 292 al. (2004) who found no significant gender difference when using unidentifiable odours in 293 classic recognition.

\section{4.2. Age differences}

295 No significant effect of age on memory strength is observed. This result is in agreement with 296 findings of studies on incidental learning and memory in other areas. In fact, there is a wealth 297 of evidence that learning ability declines with age, but almost all of the studies that show such 298 deterioration deal with explicit intentional learning and memory. All the recognition series 299 included in our dataset were based on incidental learning, which is the kind of learning 
occurring in daily life. However, one of the studies, namely Møller et al. (2007), made a comparison between incidental and intentional learning in food memory. With intentional learning, the young showed better memory performance, whereas with incidental learning the elderly were as good as the young. Other studies have consistently shown that elderly people have a well preserved implicit learning ability (see Hoyer and Lincourt, 1998).

\subsection{Influences of experimental design}

\subsubsection{Signal probability or target/distractor ratio}

307 Signal probability, i.e. the ratio between targets and distractors, seems to have no impact on response bias. This might mean that novelty detection is a biologically based mechanism that overrules the more subtle mechanisms involved in signal detection decision theory. It remains open to discussion however, whether this is due to the fact that feelings of novelty seem to

311 play a more important role than target detection. After all, participants were unaware of the 312 signal probability and although they changed their response bias over time (fig. 2) this seemed 313 unrelated to the target/distractor ratio. Experiments with varied signal probabilities using the 314 same food stimuli should provide clarity.

\section{4.3.2. Nature of the food variation}

316 The finding that qualitative changes are more effective in being correctly rejected than 317 quantitative changes might indicate that memory is tuned at detecting possibly dangerous 318 changes. Conclusions should be drawn with caution, however. Although precautions were 319 taken to have small and perceptually equivalent differences between targets and distractors, it 320 is not certain that the differences were completely comparable over all studies. 


\subsection{Nature of the learning processes involved}

Incidental learning occurs during eating allowing participants to distinguish the eaten food from new samples even if these are only slight variations of the initial food. On average, participants do not better than chance guessing when confronted with the actual target stimuli, and their memory performance depends mainly on the correct rejection of the stimuli they have not had before. The fact that this result emerges from data collected in diverse experiments with different experimental conditions, different types of food and participants from different cultures strengthens the generality and validity of the results. Although this phenomenon seems robust, one cannot conclude on the basis of this knowledge alone that food memory is tuned at detecting novelty or change, rather than at recollection of previous experiences. The low proportion of hits and the high proportion of correct rejections might be due to response bias tuned to answer "different". Here, the signal detection theory cannot provide the answer. The idea, that novelty detection is indeed the predominant mechanism in 334 incidentally learned memory, is supported by the fact that participants are more certain about 335 their "different" responses (especially correct rejections) than about their "same" responses, 336 and by "same-different" reaction time experiments showing that in olfaction, making 337 difference decisions is much faster $( \pm 200 \mathrm{~ms})$ than making same decisions (de Wijk, 1989), 338 whereas in vision same decisions are usually faster $( \pm 50 \mathrm{~ms})$ than different decisions (Luce, 339 1986; Posner, 1986). Köster et al. (In preparation), confirmed these differences between 340 olfaction and vision, using a same-different paradigm with odour stimuli as different as 341 aniseed, soap, and curry. Results showed that the reaction times to "different" responses were 342 about $300 \mathrm{~ms}$ shorter than those to the "same" responses, whereas the same subjects 343 responded "same" $50 \mathrm{~ms}$ faster than "different" when visual presentations of the odour names were used. All this, plus the fact that qualitative changes (introducing possibly dangerous new 
345 aspects) were better detected than mere quantitative changes in already present features, 346 corroborate the idea that "feelings of not knowing" play the decisive role in this type of 534

memory. Thus, odour and flavour memory seem to have the characteristics of an efficient warning system that immediately reacts to novel information.

349 Neurophysiological evidence for a memory system based on novelty detection has recently 350 been gathered. Two types of novelty detection, context novelty and feature or stimulus 351 novelty, are described. The first refers to occurrence of an event out of context, the second 352 one to occurrence of stimulus unfamiliarity (i.e., with changed features as in the present 353 distractors). These forms of novelty detection rely on different neural processes (Matsumoto 354 et al., 2007). Daselaar et al. (2006a) showed that the medial temporal lobe can detect objective 355 differences between old and new items that are not accessible to consciousness.

356 Furthermore, Daselaar et al. (2006b) found a triple dissociation in the medial temporal lobes, 357 separating memory for past events into recollection, familiarity and novelty. According to 358 them, the posterior half of the hippocampus deals with recollection, the posterior 359 parahippocampal gyrus with familiarity, whereas novelty is associated with the anterior half 360 of the hippocampus and with rhinal regions. Multiple regression analyses showed that 361 recollection, familiarity and novelty made important and independent contributions to 362 recognition memory performance.

363 All these authors stress that effective orienting towards novel stimuli is important for survival. 364 This may be why novel stimuli with 'emotional' value, like odours or deviant specimens of 365 familiar foods as used here, are efficient in capturing attention.

366 If novelty detection has survival value, it need not surprise that it seems to play a dominant 367 role in the "near" senses (olfaction, taste and texture perception) that are involved in vital 368 activities such as breathing and food ingestion. In these senses, potentially dangerous stimuli 369 are already in contact with the body at the moment of detection, and only one type of 
370 immediate reaction (fleeing for odour; spitting out for flavour) is needed to avoid serious

2371 harm by inhalation or ingestion. In these cases, there is no time and no need for identification.

For "far" senses (vision or audition) identification is useful, and more time to identify is usually available. Different dangers may demand different reaction patterns (stepping aside, 374 fighting, submission, etc.).

375 Furthermore, rejection seems to be linked to the hedonic dimension of the food, suggesting 376 that liking acts as an indicator of food safety. At the same time liking seems not related to 377 target food recollection, since hit stimuli are not more liked than those that lead to false 378 alarms and misses. This is precisely what one would expect in a memory system with a 379 primary warning function that relies on danger detection and not on reviving earlier 380 experiences.

\section{5. CONCLUSION}

382 In conclusion, incidental memory for food seems mainly involved in safeguarding our intake 383 and not in the recollection of previous experiences. This does not mean that recollection does 384 not play a role at all. It is used in conversations about previous eating experiences and 385 probably also in most food buying decisions, but in everyday eating and drinking behaviour 386 without such explicit attention, memory mechanisms like novelty and change detection 387 prevail. The fact that incidental learning in eating and drinking behaviour is probably the 388 oldest and even prenatal form of learning to be encountered in humans and that it is closely 389 linked to a vital survival function makes it a unique example for the study of the function of 390 non-verbal learning and memory.

\section{REFERENCES}


Birch, L.L. (1980). Effects of peer model's food choices and eating behaviors on preschooler's food preferences. Child Dev., 51, 489-496.

Cain, W.S., de Wijk, R., Lulejian, C., Schiet, F., See, L.C. (1998). Odor identification: Perceptual and semantic dimensions. Chem. Senses, 23, 309-326.

Cox, D.R. (1970). The analysis of binary data. London, Methuen.

Daselaar, S.M., Fleck, M.S., Cabeza, R. (2006). Triple dissociation in the medial temporal lobes: Recollection, familiarity, and novelty. J. Neurophysiol., 96, 1902-1911.

Daselaar, S.M., Fleck, M.S., Prince, S.E., Cabeza, R. (2006). The medial temporal lobe distinguishes old from new independently of consciousness. J. Neurosci., 26, 58355839.

de Wijk, R.A. (1989). Temporal factors in human olfactory perception. Unpublished Doctoral Thesis, Utrecht University.

Engen, T., Ross, B.M. (1973). Long-term memory of odors with and without verbal descriptions. J. Exp. Psychol., 100, 221-227.

Haller, R., Rummel, C., Henneberg, S., Pollmer, U., Köster, E.P. (1999). The influence of early experience with vanillin on food preference later in life. Chem. Senses, 24, 465467.

Hausner, H., Nicklaus, S., Issanchou, S., Mølgaard, C., Møller, P. (2010). Breastfeeding facilitates acceptance of a novel dietary flavour compound. Clin. Nutr., 29, 141-148.

Herz, R.S., Engen, T. (1996). Odor memory: Review and analysis. Psychon. Bull. Rev., 3, 300-313.

Hoyer, W.J., Lincourt, A.E. (1998). Aging and the development of learning, in: M.A. Stadler, P.A. French (Eds.), Handbook of implicit learning. Sage Publications, London, pp. 445-470.

Köster, E.P., Mojet, J. (2007a). Boredom and the reasons why some new food products fail, in: H. MacFie (Ed.), Consumer-led food product development. Woodhead Publishing Limited, Cambridge, England, pp. 262-280.

Köster, E.P., Mojet, J. (2007b). Theories of food choice development, in: L. Frewer, H. van Trijp (Eds.), Understanding consumers of food products. Woodhead Publishing Limited, Cambridge, England, pp. 93-214.

Köster, E.P., van der Stelt, O., Nixdorf, R.R., Linschoten, M.R.I., Dijkman, N., de Wijk, R.A., Mojet, J. (In preparation). Olfactory imagination and odour processing: three samedifferent experiments.

Köster, M.A., Prescott, J., Köster, E.P. (2004). Incidental learning and memory for three basic tastes in food. Chem. Senses, 29, 441-453.

Larsson, M. (1997). Semantic factors in episodic recognition of common odors in early and late adulthood: a review. Chem. Senses, 22, 623-633.

Larsson, M., Lovden, M., Nilsson, L.-G. (2003). Sex differences in recollective experience for olfactory and verbal information. Acta Psychol., 112, 89-103.

Laureati, M., Morin-Audebrand, L., Pagliarini, E., Sulmont-Rossé, C., Köster, E.P., Mojet, J. (2008). Food memory and its relation with age and liking: An incidental learning experiment with children, young and elderly people. Appetite, 51, 273-282.

Lawless, H.T., Cain, W.S. (1975). Recognition memory for odors. Chem. Senses, 1, 331-337.

Lehrner, J.P. (1993). Gender differences in long-term odor recognition memory: verbal versus sensory influences and the consistency of label use. Chem. Senses, 18, 17-26.

Luce, R.D. (1986). Response times. New York, Oxford University Press.

Lyman, B.J., McDaniel, M.A. (1990). Memory for odors and odor names: Modalities of elaboration and imagery. J. Exp. Psychol.: Learn., Mem. \& Cogn., 16, 656-664. 
Macmillan, N.A., Creelman, C.D. (2005). Detection Theory: a user's guide, 2nd edition ed. New York, Cambridge University Press.

Matsumoto, M., Matsumoto, K., Tanaka, K. (2007). Effects of novelty on activity of lateral and medial prefrontal neurons. Neurosc. Res., 57, 268-276.

Mennella, J.A., Jagnow, C.P., Beauchamp, G.K. (2001). Prenatal and postnatal flavor learning by human infants. Pediatrics, 107, e88.

Mojet, J., Heidema, J., Christ-Hazelhof, E. (2003). Taste perception with age: Generic or specific losses in supra-threshold intensities of five taste qualities? Chem. Senses, 28, 397-413.

Mojet, J., Köster, E.P. (2002). Texture and flavour memory in foods: An incidental learning experiment. Appetite, 38, 110-117.

Mojet, J., Köster, E.P. (2005). Sensory memory and food texture. Food Qual Pref, 16, 251266.

Møller, P., Mojet, J., Köster, E.P. (2007). Incidental and intentional flavor memory in young and older subjects. Chem. Senses, 32, 557-567.

Møller, P., Piper, D., Hartvig, D., Köster, E.P. (2009). Comparison of incidental and intentional learning of olfactory and visual stimuli. Chem. Senses, 34, A86-A86.

Møller, P., Wulff, C., Köster, E.P. (2004). Do age differences in odour memory depend on differences in verbal memory? Neuroreport, 15, 915-917.

Monnery-Patris, S., Rouby, C., Nicklaus, S., Issanchou, S. (2009). Development of olfactory ability in children: sensitivity and identification. Dev Psychobiol, 51, 268-276.

Morin-Audebrand, L., Sulmont-Rossé, C., Issanchou, S. (2006). Impact of hedonic appreciation on memory for custard dessert, in: XVII ECRO Congress, Granada, Spain, September, 4-8, 2006.

Murphy, C., Cain, W.S., Gilmore, M.M., Skinner, R.B. (1991). Sensory and semantic factors for recognition memory for odors and graphic stimuli: elderly versus young persons. Am. J. Psychol., 104, 161-192.

Posner, M.I. (1986). Chronometric explorations of mind, 2nd revised ed. Oxford, Oxford University Press.

Rabin, M.D., Cain, W.S. (1984). Odor recognition: familiarity, identifiability and encoding consistency. J. Exp. Psychol.: Learn., Mem. \& Cogn., 10, 316-325.

Schaal, B., Soussignan, R., Marlier, L. (2002). Olfactory cognition at the start of life: The perinatal shaping of selective odor responsiveness, in: C. Rouby, B. Schaal, A. Holley, D. Dubois, R. Gervais (Eds.), Olfaction, taste, and cognition. The Press Syndicate of the University of Cambridge, Cambridge, UK, pp. 421-440.

Stevenson, R.J., Prescott, J., Boakes, R.A. (1995). The acquisition of taste properties by odors. Learn. \& Motiv., 26, 433-455.

Sulmont-Rossé, C., Møller, P., Issanchou, S., E.P., K. (2008). Effect of age and food novelty on food memory. Chemosens. Percept., 1, 199-209.

Yeomans, M.R., Leitch, M., Gould, N.J., Mobini, S. (2008). Differential hedonic, sensory and behavioral changes associated with flavor-nutrient and flavor-flavor learning. Physiol. Behav., 93, 798-806. 
Table 1

487 Overview of the studies included in the present paper.

\begin{tabular}{|c|c|c|c|c|c|c|c|c|c|}
\hline \multirow{2}{*}{$\mathbf{N}^{\circ}$} & \multirow{2}{*}{ Study } & \multirow{2}{*}{ Food } & \multirow{2}{*}{$\begin{array}{c}\text { Nature of the variations } \\
\text { between target and } \\
\text { distractors }\end{array}$} & \multicolumn{3}{|c|}{ Participants } & \multirow[b]{2}{*}{$\mathbf{R} \mathbf{I}^{4}$} & \multicolumn{2}{|c|}{$\begin{array}{l}\text { Recognition } \\
\text { series }\end{array}$} \\
\hline & & & & $\mathrm{n}^{1}$ & $\mathrm{Age}^{2}$ & $M: \mathbf{W}^{3}$ & & $n^{5}$ & $T: D^{6}$ \\
\hline S1 & $\begin{array}{c}\text { Köster } \\
\text { et al., } 2004\end{array}$ & $\begin{array}{c}\text { Orange juice } \\
\text { Cream cheese } \\
\text { Yoghurt }\end{array}$ & $\begin{array}{l}\text { Sweetness, bitterness } \\
\text { Sourness, bitterness } \\
\text { Sweetness, sourness }\end{array}$ & 41 & $17-35$ & $1: 1$ & $24 h$ & $\begin{array}{l}12 \\
12 \\
12\end{array}$ & $\begin{array}{l}1: 2 \\
1: 2 \\
1: 2\end{array}$ \\
\hline S2 & $\begin{array}{l}\text { Mojet \& Köster, } \\
2005\end{array}$ & $\begin{array}{l}\text { Multi-fruit juice } \\
\text { Biscuits } \\
\text { Yoghurt }\end{array}$ & $\begin{array}{l}\text { Thickness } \\
\text { Fattiness, crispiness } \\
\text { Fattiness, thickness }\end{array}$ & 76 & $19-60$ & $4: 5$ & $8 h$ & $\begin{array}{l}8 \\
8 \\
8\end{array}$ & $\begin{array}{l}1: 1 \\
1: 1 \\
1: 1\end{array}$ \\
\hline S3 & $\begin{array}{c}\text { Møller } \\
\text { et al., } 2007\end{array}$ & $\begin{array}{l}\text { Grits soup } \\
\text { Cheese cream } \\
\text { soup }\end{array}$ & $\begin{array}{l}\text { Flavour quality } \\
\text { Flavour quality }\end{array}$ & 38 & $\begin{array}{l}21-34 \\
54-75\end{array}$ & $2: 1$ & $24 h$ & $\begin{array}{l}10 \\
10\end{array}$ & $\begin{array}{l}2: 3 \\
2: 3\end{array}$ \\
\hline S4 & $\begin{array}{l}\text { Sulmont-Rossé } \\
\text { et al., } 2008\end{array}$ & $\begin{array}{l}\text { Orange juice } \\
\text { Dairy product }\end{array}$ & $\begin{array}{l}\text { Sourness, flavour intensity } \\
\text { Sweetness, flavour intensity }\end{array}$ & 114 & $\begin{array}{l}18-34 \\
55-84\end{array}$ & $7: 10$ & $24 h$ & $\begin{array}{l}12 \\
12\end{array}$ & $\begin{array}{l}1: 1 \\
1: 1\end{array}$ \\
\hline S5 & $\begin{array}{l}\text { Laureati } \\
\text { et al., } 2008\end{array}$ & Custard & $\begin{array}{l}\text { Sweetness, thickness, } \\
\text { flavour quality }\end{array}$ & 84 & $\begin{array}{l}18-41 \\
60-83\end{array}$ & $4: 5$ & $24 h$ & 12 & $1: 3$ \\
\hline S6 & $\begin{array}{l}\text { Morin-Audebrand } \\
\text { et al., } 2006\end{array}$ & Custard & Flavour quality & 44 & $19-30$ & $1: 1$ & $7 d$ & 4 & $1: 1$ \\
\hline
\end{tabular}

$489{ }^{1}$ n: number of participants; ${ }^{2}$ Age: age range; ${ }^{3} \mathrm{M}$ :W: men/women ratio; ${ }^{4} \mathrm{RI}$ : retention interval expressed in 490 hours $(h)$ or in days $(d) ;{ }^{5} \mathrm{n}$ : number of samples in the recognition test series; ${ }^{6} \mathrm{~T}$ :D: target/distractor ratio in the 


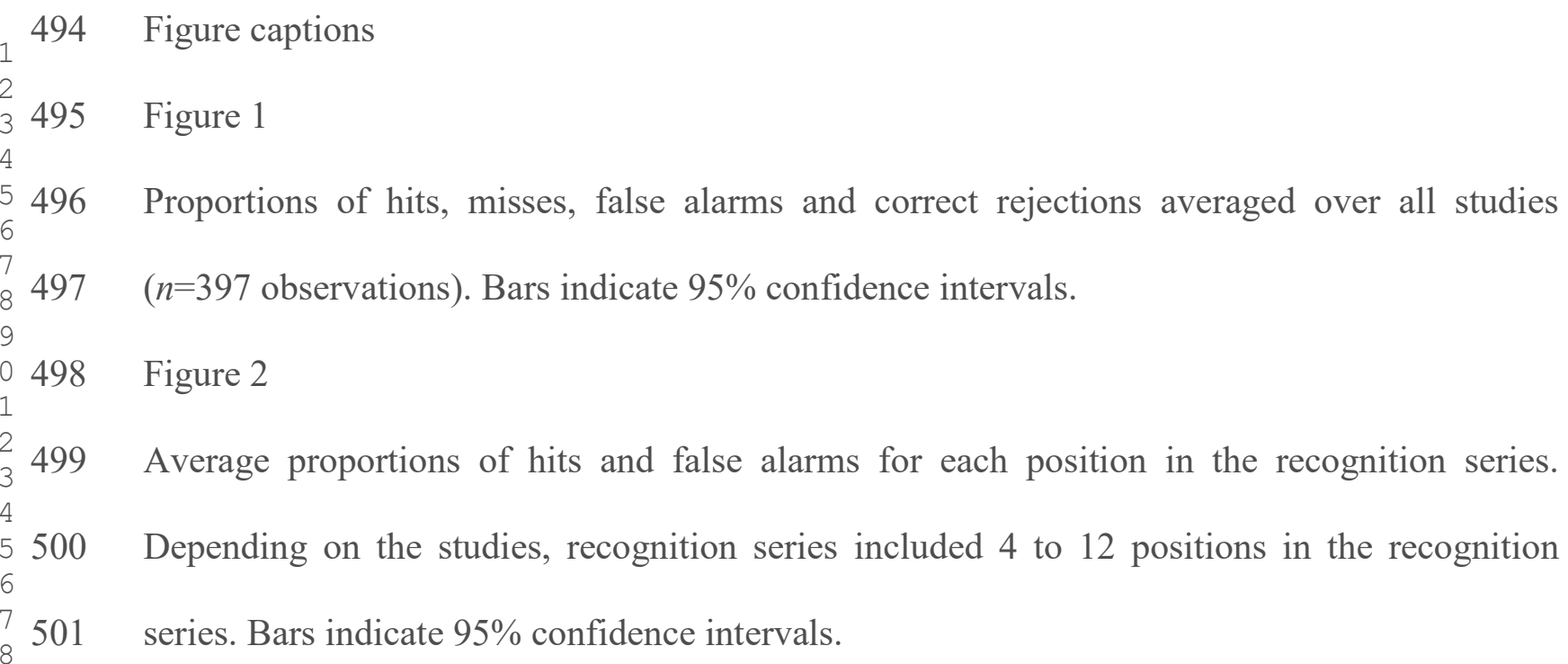


FIGURE 1

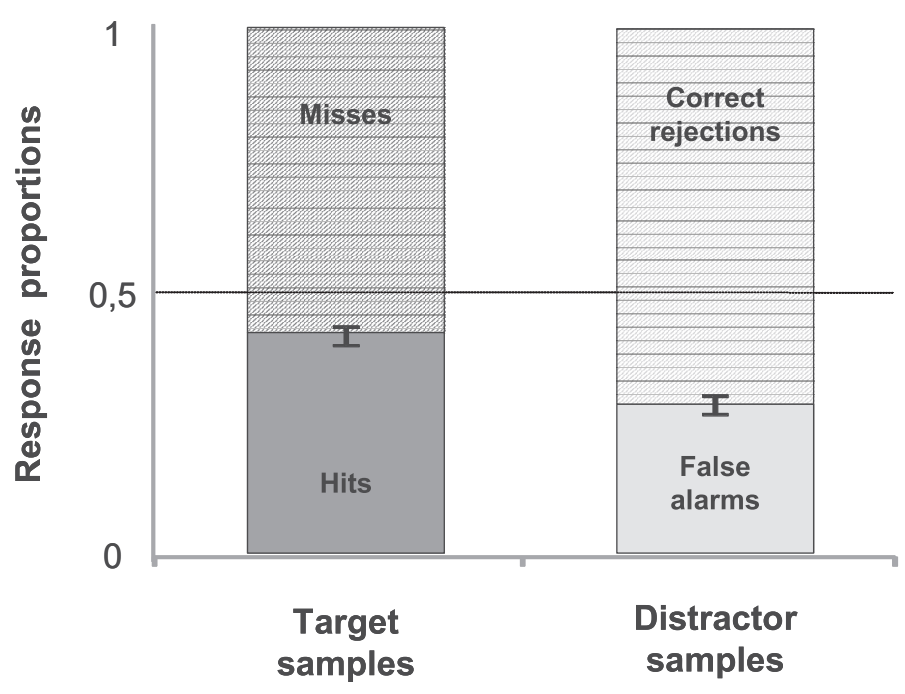


FIGURE 2

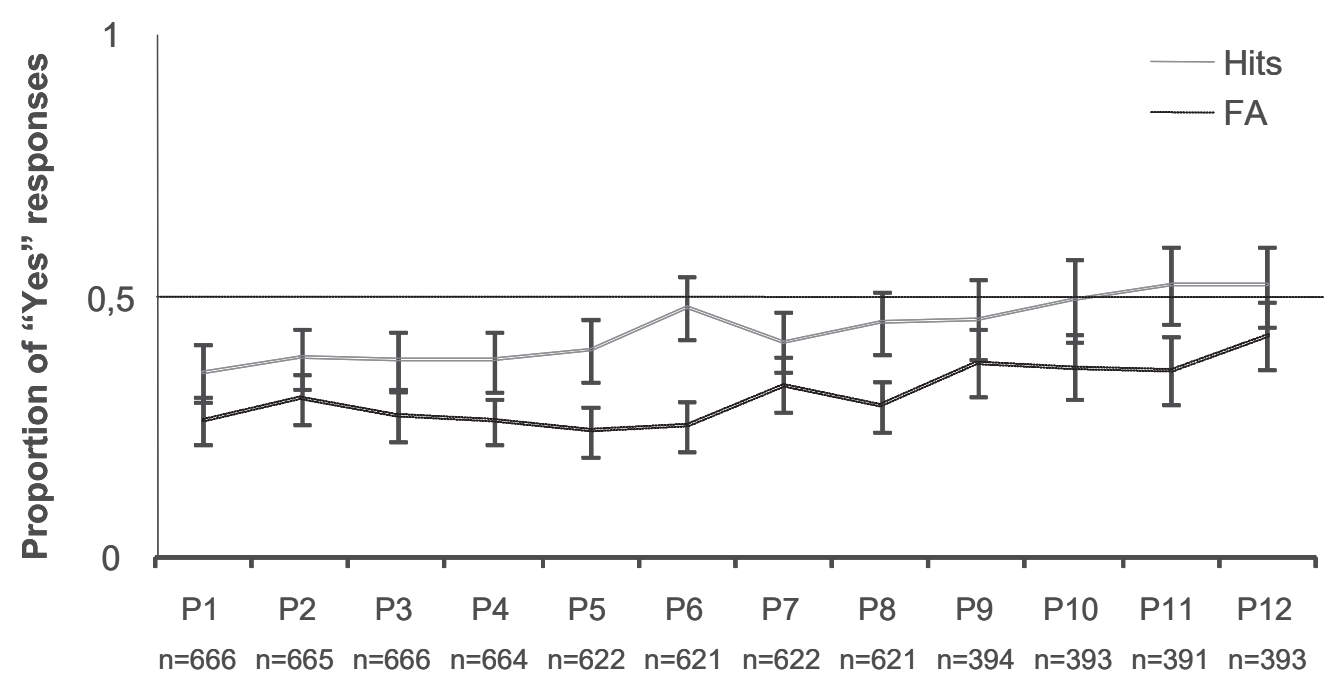

